\title{
Associations Between Socioeconomic Status and Adverse Pregnancy Outcomes: A Greater Magnitude of Perinatal Inequities in Montreal Than in Brussels
}

Mouctar Sow ( $\square$ mamasow@ulb.ac.be )

School of Public Health, University of Montreal, Quebec

Marie-France Raynault

Lea-Roback Research Centre on Social Inequalities in Health, CRCHUM, Quebec

Myriam Spiegelaere

Université Libre de Bruxelles, École de santé publique, Brussels

\section{Research Article}

Keywords: Health inequities, Perinatal inequities, poverty, income inequality, Low birth weight, Immigration, Comparative study

Posted Date: March 1st, 2021

DOl: https://doi.org/10.21203/rs.3.rs-239950/v1

License: (c) (1) This work is licensed under a Creative Commons Attribution 4.0 International License. Read Full License 
Associations between socioeconomic status and adverse pregnancy outcomes: A greater magnitude of perinatal inequities in Montreal than in Brussels

Mouctar Sow ${ }^{* 1,2,3}$, Marie-France Raynault ${ }^{1,3}$, Myriam De Spiegelaere ${ }^{2}$

Objective This paper compares the associations between socioeconomic status (SES) and 1) low birth weight (LBW) and 2) preterm birth, in Brussels and Montreal, and discusses hypotheses that may explain the differences between these two regions.

Methods This population-based study uses administrative databases from Belgian and Quebec birth records. The analysis is based on 97,844 and 214,620 singleton live births in Brussels and Montreal, respectively. Logistic regression models were developed for each region in order to estimate the relationship between SES (maternal education and income quintile) and pregnancy outcomes. The analyses were performed for all births according to the mother's origin.

Results SES is associated with LBW and preterm birth in both regions. This association varies according to the mother's birth place; the impact of SES being greater for mothers born in Belgium or Canada than for those born abroad. The main difference between the two regions concerns the magnitude of perinatal inequalities, which is greater in Montreal than in Brussels, whether among the general population, native-born mothers, or immigrant mothers.

Conclusion Significant differences in social inequalities in perinatal health are observed between Brussels and Montreal. The different characteristics of low-income and immigrant households between the two contexts help explain these results. In fact, the poor are relatively poorer in Quebec than in Belgium and live in a more unequal context.

Keywords: Health inequities, Perinatal inequities, poverty, income inequality, Low birth weight, Immigration, Comparative study

\footnotetext{
*Correspondence: mamasow@ulb.ac.be ; mamadou.mouctar.sow@umontreal.ca ; sowmouctar@yahoo.fr

${ }^{1}$ School of Public Health, University of Montreal, Quebec, Canada

${ }^{2}$ Université Libre de Bruxelles, École de santé publique, Brussels, Belgium

${ }^{3}$ Lea-Roback Research Centre on Social Inequalities in Health, CRCHUM, Quebec, Canada

Email addresses of authors: MFR: marie-france.raynault@umontreal.ca; MDS: mdespieg@ulb.ac.be
} 


\section{BACKGROUND}

Health inequities occur as early as the prenatal period and during the early years of life of the child (1-3). Measures that improve household living conditions and children's health as early as possible significantly contribute to breaking the vicious cycle of social inequalities in health (4-9).

Several types of factors, interacting through various mechanisms, can contribute to an increase or decrease in health inequalities, depending on the context. Comparing health inequalities from birth between countries or regions helps us understand the mechanisms specific to each context and identify courses of action likely to reduce such inequalities. Comparative studies of this kind, however, are few and far between. Martinson and Reichman's study (10), which compares the socioeconomic gradient with respect to LBW in the United States, Canada, Australia and Great Britain, is in keeping with this logic. The results showed a strong gradient in the USA when compared to the other countries.

This paper studies the relationship between socioeconomic status (SES) and two adverse pregnancy outcomes, low birth weight (LBW) and preterm birth, in both Brussels and Montreal. It identifies the main similarities and differences between these two regions and brings forth explanatory hypotheses for these observations. The analysis compares the scale of perinatal inequalities in the general population, much like Martinson and Reichman did (10). In addition, it compares the patterns of these inequalities between mothers born in Belgium or Canada and immigrant mothers. Such a distinction is all the more relevant since epidemiological studies show that the association between SES and pregnancy outcomes varies not only according to the contexts and indicators considered, but also according to the population studied (5,11-14). Generally speaking, the socioeconomic gradient in perinatal health among immigrants is weak or absent; this finding is described as an epidemiological paradox. These results suggest that SES and immigration interact through different mechanisms that either enhance or weaken perinatal health inequalities. The interpretation of the results will pay close attention to this aspect.

Our analysis focuses on two perinatal indicators: LBW and preterm birth, both of which are pregnancy outcomes that are strongly associated with SES (11). They increase the risk of infant mortality and health problems in children and adults. We will compare inequalities in LBW and preterm birth in Brussels and Montreal. The latter are the largest cities of Belgium and Québec respectively, and they share sociodemographic similarities, particularly with respect to 
immigration. In fact, more than half of all births come from immigrant households in both regions (14-16). The access to perinatal care is also comparable, with government health insurance plans and perinatal health prevention programs targeting vulnerable groups in both regions. However, social policies differ significantly between these two contexts, particularly with respect to minimum income protection measures, which are comparatively more generous in Belgium than in Quebec $(8,17)$.

\section{METHODS}

Two case studies were conducted and analysed from a comparative perspective. A study investigating the association between SES and pregnancy outcomes was conducted in each city. In Brussels, the data is based on singleton live births spanning from 2005 to 2010, which amount to 97,844 . This data is the result of the combination of three administrative files: the birth register, containing the health data of newly born babies; the Crossroads Bank of Social Security (Banque Carrefour de la Sécurité Sociale), which includes socioeconomic data on households; and the national register, which encloses data on migration. To our knowledge, this is the first study to combine these data in Belgium. For the administrative region of Montreal, the data comes from birth registers, and is based on 214,620 singleton live births that occurred between 2003 and 2012.

Low birth weight (i.e. less than $2500 \mathrm{~g}$ ) and preterm delivery (i.e. birth before 37 full weeks of gestational age) were analysed according to maternal education and household income. Logistic regression models were used to estimate the odds ratios of the associations between perinatal indicators and SES. The adjustment covariates were relationship status (being in a couple or not), maternal age, parity, and child sex. The analyses were first carried out for all births, then stratified by immigration status, using the mother's country of birth as a proxy.

Maternal education was divided into three categories, taking into account the difference in school systems and diplomas in Belgium and Quebec. Mothers considered to have a high level of education are those who have obtained a university degree, or any kind of higher education degree in Belgium. This correspond to who have completed at least 16 years of education in Belgium or Quebec. Mothers with less than 12 years of education are considered to be less educated: they did not graduate secondary school in Belgium or go beyond Secondary V in Quebec. Women who have 
completed at least 12 years of education but did not obtain a higher education degree are considered to have an intermediate level of education.

Household income was categorised into quintiles, taking into account the available data in each region. In Brussels, the information is based on households and is derived from social security data. ${ }^{17}$ In order to be able to compare households, these income data are based on household size, using the modified OECD scale, yielding an "equivalised disposable income". (18) The database contains equivalent incomes categorised by deciles. This means that for any household that had a child during the study period, we are able to determine which income decile of the general population it falls into, but not its exact income level. In Montreal, the average income at the level of the dissemination area was considered. The dissemination area is the smallest geographic unit for which Statistics Canada releases census data (19) This indicator is usually used to analyse health inequalities in Quebec (20,21). Geographic indicators are considered good proxies for individual situations when they relate to small, socio-demographically homogeneous agglomerations such as Montreal (20). This variable was integrated into the birth register by way of postal codes. Each household was assigned the average income of its geographic unit. The variable was then categorised into quintiles according to the distribution of the study population. These quintiles are constructed on the population of mothers who gave birth during the study period, and therefore not on the general population, as is the case in Brussels.

\section{RESULTS}

\section{Characteristics of births in Brussels and Montreal: Important differences according to mother's birthplace}

There are on average around 16,300 singleton live births per year in Brussels and 21,500 in Montreal for the time periods studied. In both regions, more than half of the births were to foreignborn mothers. The distribution of SES according to the mother's birthplace differs between Brussels and Montreal (Table 1). The percentage of less educated mothers is relatively higher in Brussels than in Montreal, whereas that of well-educated mothers is higher in Montreal than in Brussels. The difference between the two regions is even greater when comparing the situation of immigrant mothers. In Brussels, foreign-born mothers have lower income and lower education levels than those born in Belgium, while in Montreal the level of education is not correlated to maternal 
birthplace, and the income gap between immigrant mothers and Canadian-born mothers is less pronounced than in Brussels. The proportion of single mothers is higher in Brussels than in Montreal. The figures do not differ according to the mother's birthplace for both regions.

Table 1. Characteristics of mothers and newborns in Brussels and Montreal

\begin{tabular}{|c|c|c|c|c|c|c|}
\hline & \multicolumn{3}{|c|}{ BRUSSELS (2005-2010) } & \multicolumn{3}{|c|}{ MONTREAL (2003-2012) } \\
\hline & \multicolumn{3}{|c|}{ Maternal birth place } & \multicolumn{3}{|c|}{ Maternal birth place } \\
\hline & All Births & Belgium & Immigrants & All Births & Canada & Immigrants \\
\hline $\mathrm{N}$ & 97844 & 39591 & 55333 & 214620 & 97520 & 112468 \\
\hline$\%$ of births & 100 & 40.46 & 56.55 & 100 & 45.4 & 52.4 \\
\hline Maternal education $(\mathbf{n})$ & 89864 & 37085 & 50175 & 200943 & 92943 & 104476 \\
\hline High (\%) & 31.66 & 40.64 & 24.66 & 46.14 & 47.23 & 45.30 \\
\hline Intermediate (\%) & 35.16 & 35.14 & 35.27 & 29.16 & 29.36 & 28.83 \\
\hline Low (\%) & 33.17 & 24.22 & 40.07 & 24.70 & 23.41 & 25.87 \\
\hline Income Quintile (n) & 88655 & 38638 & 48937 & 211265 & 95642 & 111052 \\
\hline Top (\%) & 13.10 & 20.28 & 7.26 & 20.00 & 26.57 & 14.52 \\
\hline Fourth (\%) & 11.75 & 18.47 & 6.50 & 20.00 & 23.34 & 17.08 \\
\hline Midlle (\%) & 15.27 & 18.65 & 12.69 & 20.00 & 20.35 & 19.59 \\
\hline Second (\%) & 18.48 & 16.23 & 20.35 & 20.00 & 17.75 & 21.91 \\
\hline Bottom (\%) & 41.40 & 26.36 & 53.20 & 20.00 & 12.00 & 26.89 \\
\hline Household situation (n) & 88677 & 37362 & 50256 & 208249 & 95139 & 108811 \\
\hline Lives alone (\%) & 16.16 & 16.40 & 15.91 & 9.94 & 10.18 & 9.69 \\
\hline Maternal age $(n)$ & 97844 & 39591 & 55333 & 214620 & 97520 & 112468 \\
\hline$<20(\%)$ & 2.39 & 2.39 & 2.35 & 2.17 & 3.30 & 1.16 \\
\hline$\geq 40(\%)$ & 4.31 & 2.92 & 5.33 & 6.62 & 5.27 & 7.86 \\
\hline Previous births (n) & 97234 & 39381 & 54945 & 214620 & 97520 & 112468 \\
\hline $0(\%)$ & 47.70 & 52.09 & 44.13 & 48.65 & 53.83 & 43.93 \\
\hline $1-2(\%)$ & 43.70 & 41.73 & 45.37 & 45.36 & 41.44 & 48.96 \\
\hline $3(\%)$ & 8.60 & 6.18 & 10.50 & 5.99 & 4.73 & 7.11 \\
\hline LBW (n) & 97844 & 39381 & 55333 & 214589 & 97509 & 112463 \\
\hline$\%$ & 4.64 & 5.08 & 4.31 & 4.49 & 4.32 & 4.65 \\
\hline Preterm $(\mathrm{n})$ & 95490 & 38670 & 54009 & 214587 & 97509 & 112462 \\
\hline$\%$ & 5.22 & 5.48 & 5.02 & 5.82 & 5.72 & 5.95 \\
\hline
\end{tabular}




\section{Associations Between SES and Adverse Pregnancy Outcomes}

\section{Greater perinatal inequalities in Montreal than in Brussels}

In both regions, newborns of highly educated or high-income mothers are at lower risk of LBW or preterm birth than those of lower SES mothers (Table 2). However, inequalities pertaining to education levels and SES are more pronounced in Montreal for both perinatal indicators, before and after adjusting for maternal and child characteristics (income, education, marital status, age, parity, and sex of the child). For example, in Brussels, the risk of LBW for a newborn whose mother is less educated compared to a newborn whose mother is highly educated is, after adjustment, 1.20 $(\mathrm{CI}=1.09-1.32)$ in Brussels and $1.67(\mathrm{CI}=1.58-1.77)$ in Montreal. (Table 2). Furthermore, in Montreal, the relationship between SES and perinatal health in the general population follows a classic health gradient, with the risk of poorer perinatal health being inversely proportional to SES. In Brussels, however, this gradient is present for education but is less pronounced or even nonexistent for household income. 
Table 2. Associations between SES and birth outcomes. Brussels vs Montreal

\begin{tabular}{|r|ccc|ccc|}
\multicolumn{1}{c|}{} & \multicolumn{5}{|c|}{ LBW } & \multicolumn{4}{c|}{ MONTREAL } \\
\hline Maternal education & $\%$ & ORs $(95 \% \mathrm{Cl})$ & adjusted ORs* & $\%$ & ORs $(95 \% \mathrm{Cl})$ & adjusted ORs* \\
High & 4.08 & 1 & & & & \\
Intermediate & 4.81 & $1.18(1.10-1.29)^{\mathrm{a}}$ & $1.16(1.05-1.26)^{\mathrm{b}}$ & 4.50 & $1.24(1.17-1.30)^{\mathrm{a}}$ & $1.26(1.19-1.33)^{\mathrm{a}}$ \\
Low & 4.80 & $1.19(1.09-1.28)^{\mathrm{a}}$ & $1.20(1.09-1.32)^{\mathrm{a}}$ & 5.86 & $1.64(1.56-1.72)^{\mathrm{a}}$ & $1.67(1.58-1.77)^{\mathrm{a}}$ \\
\hline Top & 3.72 & 1 & & & & \\
Fourth & 4.59 & $1.24(1.09-1.42)^{\mathrm{b}}$ & $1.18(1.03-1.35)^{\mathrm{c}}$ & 4.25 & $1.18(1.10-1.26)^{\mathrm{a}}$ & $1.08(1.01-1.16)^{\mathrm{c}}$ \\
Midlle & 4.83 & $1.31(1.16-1.49)^{\mathrm{a}}$ & $1.21(1.05-1.38)^{\mathrm{b}}$ & 4.58 & $1.27(1.19-1.36)^{\mathrm{a}}$ & $1.15(1.07-1.23)^{\mathrm{a}}$ \\
Second & 4.49 & $1.22(1.07-1.37)^{\mathrm{b}}$ & $1.15(1.01-1.32)^{\mathrm{c}}$ & 4.69 & $1.31(1.22-1.40)^{\mathrm{a}}$ & $1.14(1.05-1.21)^{\mathrm{a}}$ \\
Bottom & 4.66 & $1.26(1.13-1.41)^{\mathrm{a}}$ & $1.12(0.98-1.27)$ & 5.35 & $1.50(1.40-1.60)^{\mathrm{a}}$ & $1.29(1.20-1.38)^{\mathrm{a}}$ \\
\hline
\end{tabular}

\begin{tabular}{|c|c|c|c|c|c|c|}
\hline & \multicolumn{6}{|c|}{ PRETERM } \\
\hline & \multicolumn{3}{|c|}{ BRUSSELS } & \multicolumn{3}{|c|}{ MONTREAL } \\
\hline & $\%$ & ORs $(95 \% \mathrm{Cl})$ & adjusted ORs* & $\%$ & ORs $(95 \% \mathrm{Cl})$ & adjusted ORs* \\
\hline \multicolumn{7}{|l|}{ Maternal education } \\
\hline High & 4.68 & 1 & 1 & 4.77 & 1 & 1 \\
\hline Intermediate & 5.38 & $1.16(1.07-1.25)^{\mathrm{a}}$ & $1.12(1.03-1.22)^{b}$ & 5.95 & $1.26(1.21-1.32)^{\mathrm{a}}$ & $1.28(1.22-1.34)^{\mathrm{a}}$ \\
\hline Low & 5.40 & $1.16(1.08-1.25)^{\mathrm{a}}$ & $1.14(1.03-1.23)^{b}$ & 7.40 & $1.59(1.52-1.67)^{\mathrm{a}}$ & $1.60(1.52-1.68)^{\mathrm{a}}$ \\
\hline \multicolumn{7}{|l|}{ Income } \\
\hline Top & 4.46 & 1 & 1 & 5.10 & 1 & 1 \\
\hline Fourth & 5.07 & $1.14(1.01-1.29)^{\mathrm{c}}$ & $1.11(0.97-1.26)$ & 5.57 & $1.09(1.03-1.16)^{b}$ & $1.01(0.95-1.07)$ \\
\hline Midlle & 5.15 & $1.16(1.03-1.30)^{\mathrm{c}}$ & $1.11(0.97-1.25)$ & 5.97 & $1.18(1.11-1.25)^{\mathrm{a}}$ & $1.07(1.01-1.14)^{\mathrm{c}}$ \\
\hline Second & 5.08 & $1.15(1.02-1.28)^{\mathrm{c}}$ & $1.08(0.95-1.23)$ & 6.05 & $1.20(1.13-1.27)^{\mathrm{a}}$ & $1.04(0.98-1.11)$ \\
\hline Bottom & 5.28 & $1.19(1.08-1.32)^{\mathrm{b}}$ & $1.07(0.95-1.21)$ & 6.50 & $1.29(1.22-1.37)^{\mathrm{a}}$ & $1.13(1.06-1.20)^{\mathrm{a}}$ \\
\hline
\end{tabular}

"ORs adjusted for income, education, marital status, parity, mother's age, and child's sex.

${ }^{\mathrm{a}} \leq 0.001 ;{ }^{\mathrm{b}} \leq 0.01 ;{ }^{\mathrm{c}} \leq 0.05$ 


\section{Greater impact of SES among natives than immigrants}

In both regions, the association between SES and perinatal health differs according to the mother's birthplace (Tables 3 and 4). The impact of SES is stronger for mothers born in Belgium and Canada than for those born abroad. Among native mothers, all associations are significant, before and after adjusting for maternal and child characteristics. The magnitude of perinatal inequalities is, however, greater for mothers born in Canada than for those born in Belgium (Table 3). The socioeconomic gradient in perinatal health is less marked among immigrant mothers than native mothers. This finding is more pronounced in Brussels than in Montreal, particularly for education, which is associated with pregnancy outcomes in Montreal but not in Brussels (Table 4).

Table 3. Associations between SES and birth outcomes among natives-born women, Brussels vs Montreal

\begin{tabular}{|c|c|c|c|c|c|c|}
\hline & \multicolumn{6}{|c|}{ LBW } \\
\hline & \multicolumn{3}{|c|}{ Belgian natives-born } & \multicolumn{3}{|c|}{ Canadian natives-born } \\
\hline & $\%$ & ORs $(95 \% \mathrm{Cl})$ & Adjusted ORs* & $\%$ & ORs $(95 \% \mathrm{Cl})$ & Adjusted ORs* \\
\hline \multicolumn{7}{|l|}{ Maternal education } \\
\hline High & 4.10 & 1 & 1 & 3.38 & 1 & 1 \\
\hline Intermediate & 5.23 & $1.29(1.15-1.44)^{a}$ & $1.23(1.09-1.39)^{\mathrm{a}}$ & 4.21 & $1.26(1.16-1.36)^{\mathrm{a}}$ & $1.25(1.15-1.36)^{\mathrm{a}}$ \\
\hline Low & 6.27 & $1.56(1.39-1.75)^{a}$ & $1.45(1.23-1.66)^{\mathrm{a}}$ & 6.20 & $1.89(1.75-2.04)^{\mathrm{a}}$ & $1.81(1.65-1.98)^{\mathrm{a}}$ \\
\hline \multicolumn{7}{|l|}{ Income quintile } \\
\hline Top & 3.89 & 1 & 1 & 3.31 & 1 & 1 \\
\hline Fourth & 4.76 & $1.23(1.05-1.44)^{b}$ & $1.16(0.98-1.37)$ & 4.01 & $1.22(1.11-1.34)^{\mathrm{a}}$ & $1.09(0.98-1.20)$ \\
\hline Middle & 5.02 & $1.30(1.11-1.52)^{b}$ & $1.16(0.97-1.37)$ & 4.62 & $1.42(1.29-1.56)^{\mathrm{a}}$ & $1.21(1.09-1.34)^{\mathrm{a}}$ \\
\hline Second & 5.09 & $1.32(1.13-1.55)^{\mathrm{a}}$ & $1.22(1.02-1.46)^{c}$ & 4.93 & $1.52(1.38-1.67)^{\mathrm{a}}$ & $1.23(1.11-1.37)^{\mathrm{a}}$ \\
\hline \multirow[t]{4}{*}{ Bottom } & 5.59 & $1.46(1.27-1.69)^{a}$ & $1.24(1.05-1.48)^{c}$ & 5.82 & $1.81(1.63-2.00)^{\mathrm{a}}$ & $1.37(1.22-1.53)^{\mathrm{a}}$ \\
\hline & \multicolumn{6}{|c|}{ Preterm } \\
\hline & \multicolumn{3}{|c|}{ Belgian natives-born } & \multicolumn{3}{|c|}{ Canadian natives-born } \\
\hline & $\%$ & ORs $(95 \% \mathrm{Cl})$ & Adjusted ORs* & $\%$ & OR's (95\% Cl) & Adjusted ORs* \\
\hline \multicolumn{7}{|l|}{ Maternal education } \\
\hline High & 4.72 & 1 & 1 & 4.58 & 1 & 1 \\
\hline Intermediate & 5.70 & $1.22(1.09-1.35)^{a}$ & $1.15(1.02-1.29)^{c}$ & 5.75 & $1.27(1.19-1.36)^{\mathrm{a}}$ & $1.28(1.19-1.38)^{\mathrm{a}}$ \\
\hline Low & 6.34 & $1.36(1.22-1.53)^{a}$ & $1.23(1.07-1.41)^{b}$ & 7.70 & $1.74(1.63-1.86)^{\mathrm{a}}$ & $1.69(1.57-1.83)^{\mathrm{a}}$ \\
\hline \multicolumn{7}{|l|}{ Income quintile } \\
\hline Top & 4.55 & 1 & 1 & 4.86 & 1 & 1 \\
\hline Fourth & 5.16 & $1.14(0.98-1.32)$ & $1.10(0,94-1.28)$ & 5.66 & $1.17(1.08-1.27)^{\mathrm{a}}$ & $1.05(0.96-1.14)$ \\
\hline Middle & 5.20 & $1.15(0.99-1.34)$ & $1.07(0.91-1.25)$ & 5.88 & $1.22(1.13-1.33)^{\mathrm{a}}$ & $1.06(0.97-1.15)$ \\
\hline Second & 5.58 & $1.24(1.06-1.44)^{c}$ & $1.16(0.97-1.37)$ & 6.22 & $1.30(1.19-1.41)^{\mathrm{a}}$ & $1.07(0.98-1.17)^{\circ}$ \\
\hline Bottom & 5.84 & $1.30(1.13-1.49)^{a}$ & $1.22(1.03-1.44)^{c}$ & 6.87 & $1.44(1.32-1.58)^{\mathrm{a}}$ & $1.13(1.02-1.25)^{c}$ \\
\hline
\end{tabular}

*ORs adjusted for income, education, marital status, parity, mother's age, and child's sex.

a $\leq 0.001 ;{ }^{b} \leq 0.01 ;{ }^{c} \leq 0.05$ 
Table 4. Associations between SES and birth outcomes among immigrants. Brussels vs Montreal

\begin{tabular}{|c|c|c|c|c|c|c|}
\hline & \multicolumn{6}{|c|}{ LBW } \\
\hline & \multicolumn{3}{|c|}{ BRUSSELS } & \multicolumn{3}{|c|}{ MONTREAL } \\
\hline & $\%$ & ORs $(95 \% \mathrm{Cl})$ & adjusted ORs* & $\%$ & ORs $(95 \% \mathrm{Cl})$ & adjusted ORs* \\
\hline \multicolumn{7}{|l|}{ Maternal education } \\
\hline High & 4.08 & 1 & 1 & 3.94 & 1 & 1 \\
\hline Intermediate & 4.50 & $1.11(0.98-1.24)$ & $1.05(0.92-1.20)$ & 4.80 & $1.23(1.15-1.32)^{a}$ & $1.27(1.18-1.37)^{\mathrm{a}}$ \\
\hline Low & 4.12 & $1.01(0.90-1.13)$ & $1.03(0.89-1.18)$ & 5.62 & $1.45(1.35-1.56)^{\mathrm{a}}$ & $1.57(1.45-1.69)^{\mathrm{a}}$ \\
\hline \multicolumn{7}{|l|}{ Income Quintile } \\
\hline Top & 3.29 & 1 & 1 & 4.13 & 1 & 1 \\
\hline Fourth & 4.23 & $1.30(1.01-1.67)^{c}$ & $1.22(0.93-1.59)$ & 4.54 & $1.10(0.99-1.22)$ & $1.04(0.93-1.16)$ \\
\hline Midlle & 4.59 & $1.41(1.13-1.76)^{b}$ & $1.38(1.09-1.75)^{b}$ & 4.61 & $1.12(1.01-1.24)$ & $1.05(0.94-1.17)$ \\
\hline Second & 4.10 & $1.26(1.02-1.55)^{c}$ & $1.28(1.01-1.61)^{\mathrm{c}}$ & 4.53 & $1.10(0.99-1.21)$ & $1.00(0.90-1.10)$ \\
\hline Bottom & 4.28 & $1.31(1.08-1.60)^{\mathrm{b}}$ & $1.26(1.02-1.57)^{\mathrm{c}}$ & 5.18 & $1.27(1.15-1.39)^{\mathrm{a}}$ & $1.16(1.04-1.27)^{\mathrm{a}}$ \\
\hline
\end{tabular}

\begin{tabular}{|c|c|c|c|c|c|c|}
\hline & \multicolumn{6}{|c|}{ PRETERM } \\
\hline & \multicolumn{3}{|c|}{ BRUSSELS } & \multicolumn{3}{|c|}{ MONTREAL } \\
\hline & $\%$ & ORs $(95 \% \mathrm{Cl})$ & adjusted ORs* & $\%$ & ORs $(95 \% \mathrm{Cl})$ & adjusted ORs* \\
\hline \multicolumn{7}{|l|}{ Maternal education } \\
\hline High & 4.65 & 1 & 1 & 4.97 & 1 & 1 \\
\hline Intermediate & 5.16 & $1.11(1.00-1.24)$ & $1.08(0.95-1.23)$ & 6.19 & $1.26(1.18-1.34)^{a}$ & $1.28(1.20-1.36)^{\mathrm{a}}$ \\
\hline Low & 4.97 & $1.07(0.96-1.19)$ & $1.08(0.95-1.23)$ & 7.21 & $1.48(1.39-1.58)^{\mathrm{a}}$ & $1.53(1.43-1.64)^{\mathrm{a}}$ \\
\hline \multicolumn{7}{|l|}{ Income Quintile } \\
\hline Top & 4.22 & 1 & 1 & 5.53 & 1 & 1 \\
\hline Fourth & 4.92 & $1.17(0.93-1.48)$ & $1.17(0.92-1.49)$ & 5.52 & 0.99 (0.91-1.09) & $0.93(0.84-1.02)$ \\
\hline Midlle & 5.08 & $1.21(0.99-1.48)$ & $1.23(0.98-1.52)$ & 6.14 & $1.12(1.02-1.22)^{c}$ & $1.05(0.96-1.15)$ \\
\hline Second & 4.76 & $1.13(0.94-1.37)$ & $1.12(0.91-1.38)$ & 5.97 & $1.08(0.99-1.18)$ & $0.98(0.90-1.08)$ \\
\hline Bottom & 5.03 & $1.20(1.01-1.43)^{c}$ & $1.11(0.91-1.35)$ & 6.39 & $1.17(1.07-1.26)^{\mathrm{a}}$ & $1.07(0.98-1.16)$ \\
\hline
\end{tabular}

*ORs adjusted for income, education, marital status, parity, mother's age, and child's sex.

a $\leq 0.001 ;{ }^{b} \leq 0.01 ;{ }^{c} \leq 0.05$ 


\section{DISCUSSION}

The use of large-scale administrative databases has made it possible to assess perinatal inequalities in Brussels and Montreal. The analysis reveals similarities, but also notable differences between the two regions. First, perinatal inequalities are observed in both regions, but they are more pronounced in Montreal than in Brussels. Second, the association between SES and perinatal health varies according to the mother's place of birth, with the impact of SES being greater for mothers born in Belgium or Canada than for those born abroad. However, the link between SES and perinatal health among immigrants is weaker in Brussels than in Montreal.

How can we explain the greater extent of social inequalities in perinatal health in Montreal than in Brussels? Two complementary hypotheses will be discussed below: on the one hand, the existence of greater social inequalities in Montreal than in Brussels and, on the other hand, the lower vulnerability of immigrants with low SES in Brussels.

\section{Greater social inequalities in Montreal than in Brussels}

The classic social gradient observed can be explained by stronger protective factors and lower health risk factors as one moves up the social ladder. The greater vulnerability of low-income mothers can be explained, for example, by insufficient income to acquire goods and services and by psychosocial consequences - namely social participation and the adverse consequences of social comparison. By comparing the two contexts, we can observe similar poverty rates: in 2016, if we consider a poverty threshold set at $50 \%$ of the median income, the poverty rate of the general population was at $8.3 \%$ in Belgium and $9.5 \%$ in Quebec $(22,23)$ and the child poverty rate was at $9.8 \%$ in Belgium and $9.7 \%$ in Quebec (under 16 years of age) $(23,24)$. Poverty rates at the regional level are also similar $-18.9 \%$ in Brussels and $16.2 \%$ in Montreal $(22,23)$.

While the poverty rates are similar, the intensity of poverty, however, is greater in Quebec than in Belgium. The intensity of poverty is measured by the poverty gap, which is a relative estimate of the difference between the average or median income of low-income households and the relative poverty threshold. In Belgium, the poverty gap was at $21.6 \%$ in 2016, meaning the disposable income of poor people was on average 21.6\% (25) below the poverty threshold. In Quebec, however, the poverty gap was at 30.3\% (Source: Quebec Statiscal Institute). This difference can 
be explained in particular by a lower replacement income for people outside the labour market in Quebec. This is the case for welfare: for a single person with no work income, was $11 \%$ below the relative poverty line (50\% threshold) in Belgium and 64\% in Quebec. Unemployment insurance benefits replace the income of the unemployed at a rate of $65 \%$ in Belgium and $55 \%$ in Quebec on average and for a longer period of time in Belgium than in Quebec (26). Income inequality, as measured by the Gini index in 2017, is also more pronounced in Quebec (0.32) than in Belgium (0. 26) (22,27).

All in all, if the proportion of low-income households is similar in both regions, the poor are relatively poorer in Quebec than in Belgium and live in a more unequal context. These differences between the two contexts could help explain the greater magnitude of perinatal health inequalities in Montreal than in Brussels.

\section{Lower vulnerability of immigrants with low SES in Brussels, particularly in Brussels?}

In both regions, the impact of SES is greater among mothers born in Belgium and Canada than among those born abroad. This difference according to the mother's birthplace is more pronounced in Brussels than in Montreal, particularly with respect to maternal education. While in Montreal the risk of LBW or preterm birth progressively decreases as the education level increases, in Brussels, education is not at all associated with these risks in the case of immigrant mothers.

The weakness or absence of the socioeconomic gradient, mainly in terms of education level, pertaining to perinatal health among immigrants has also been highlighted in other studies (1214,28).

This finding is directly linked to the relatively low prevalence of LBW observed among some immigrant mothers with low SES: in the case of mothers with a low level of education, LBW is less prevalent among immigrants than among native women, particularly in Brussels. A study that compares immigrant and native mothers with equal SES confirms the lower vulnerability of immigrant women in Brussels to LBW and preterm delivery (29). One explanation is the presence of protective factors that reduce the vulnerability of certain less educated immigrant mothers during pregnancy. For instance, the study conducted in Brussels showed that $60 \%$ of Brussels mothers of Maghrebi origin stayed at home during their pregnancy $(14,16)$. Not being exposed to precarious working conditions during pregnancy could have a beneficial effect on the course of the pregnancy and the health of both mother and child, and contribute to the low risk of giving birth to LBW and 
preterm infants for Maghrebi mothers with a low SES. Another explanatory factor relates to lifestyle habits: tobacco and alcohol consumption is much less frequent among immigrants than among native women $(30,31)$.

The smaller social gradient in Brussels can be explained by a compositional effect: there are proportionally more immigrant mothers in low SES households in Brussels than in Montreal. In Brussels, $72 \%$ of very low-income households are immigrant households, as opposed to $56 \%$ in Montreal, and 69\% of mothers with a low level of education are immigrants in Brussels compared to $54 \%$ in Montreal. The lower impact of income and education on perinatal health among immigrant mothers, particularly in Brussels, could help explain the lower inequalities in preterm birth and low birth weight in Brussels.

\section{CONCLUSION}

Two regions with similar sociodemographic and perinatal indicators in the general population show significant differences in terms of perinatal health inequities. These results could be explained by the differing characteristics of low-income and immigrant households between the two contexts. Moreover, the analysis suggests that a comparison of immigration and poverty contexts, as well as the public policies related to these factors, can explain certain results in perinatal epidemiology. Future studies seeking to understand the mechanisms that lead to perinatal inequalities in different contexts should take this into account. 


\section{Declarations}

\section{Ethics approval and consent to participate}

Approval was obtained from two ethics committee: the Université de Montréal health research ethics board (\# 15-004-CERES-D) and the belgian Commission for the Protection of Privacy (\# STAT 04-2014).

Participant consent was not necessary as this study involved the use of a de-identified database.

The requirement of the informed consent is waived by the two ethics committee.

All methods were carried out in accordance with relevant guidelines and regulations.

Consent for publication Not applicable.

\section{Availability of data and materials}

Belgian data are available from the authors upon reasonable request and with permission of Commission for the Protection of Privacy (CPP). Canadian data are available at the Québec InterUniversity Center for Social Statistics (QICSS)

Competing interests The authors declare that they have no competing interests.

\section{Funding}

This research was supported by Fonds National de la Recherche Scientifique (FNRS-Belgium) grant number [ $\mathrm{n}^{\circ}$ 22329302], Fonds de la Recherche du Québec-Société et Culture (FRQSC) grant number [197077], and Lea Roback research Centre on social inequalities in health of Montreal.

\section{Authors' Contributions}

MS performed the design of the study, the statistical analysis and wrote the draft of the manuscript. MFR and MDS have been involved in revising the manuscript. All authors read and approved the final version of the article.

\section{Acknowledgements}

We would like to thank Statistics Belgium (DGSIE) and the Québec Inter-University Center for Social Statistics (QICSS) for providing the data. 


\section{References}

1. Aizer A, Currie J. The intergenerational transmission of inequality: Maternal disadvantage and health at birth. Science. 2014;344(6186):856-61.

2. Hafkamp-de Groen E, Van Rossem L, De Jongste JC, Mohangoo AD, Moll HA, Jaddoe $\mathrm{VWV}$, et al. The role of prenatal, perinatal and postnatal factors in the explanation of socioeconomic inequalities in preschool asthma symptoms: the Generation R Study. J Epidemiol Community Health. 2012;66(11):1017-24.

3. Béatrice N, Lise G, Victoria Z, Louise S. Longitudinal patterns of poverty and health in early childhood: exploring the influence of concurrent, previous, and cumulative poverty on child health outcomes. BMC Pediatr. 2012;12(1):141.

4. Cheng TL, Johnson SB, Goodman E. Breaking the Intergenerational Cycle of Disadvantage: The Three Generation Approach. PEDIATRICS. 2016;137(6):e20152467-e20152467.

5. Kim D, Saada A. The Social Determinants of Infant Mortality and Birth Outcomes in Western Developed Nations: A Cross-Country Systematic Review. Int J Environ Res Public Health. 2013;10(6):2296-335.

6. Komro KA, Burris S, Wagenaar AC. Social Determinants of Child Health: Concepts and Measures for Future Research. Health Behav Policy Rev. 2014;1(6):432-45.

7. Marmot M, Friel S, Bell R, Houweling TA, Taylor S. Closing the gap in a generation: health equity through action on the social determinants of health. The Lancet. 2008;372(9650):1661-9.

8. Sow M, De Spiegelaere M, Raynault M-F. Evaluating the effect of income support policies on social health inequalities (SHIs) at birth in Montreal and Brussels using a contextualised comparative approach and model family method: a study protocol. BMJ Open. 2018;8(9):e024015.

9. Strully KW, Rehkopf DH, Xuan Z. Effects of Prenatal Poverty on Infant Health: State Earned Income Tax Credits and Birth Weight. Am Sociol Rev. 2010;75(4):534-62. Available from: http://asr.sagepub.com/cgi/doi/10.1177/0003122410374086

10. Martinson ML, Reichman NE. Socioeconomic Inequalities in Low Birth Weight in the United States, the United Kingdom, Canada, and Australia. Am J Public Health. 2016;106(4):74854.

11. Blumenshine P, Egerter S, Barclay CJ, Cubbin C, Braveman PA. Socioeconomic Disparities in Adverse Birth Outcomes. Am J Prev Med. 2010;39(3):263-72.

12. Goldman N, Kimbro RT, Turra CM, Pebley AR. Socioeconomic Gradients in Health for White and Mexican-Origin Populations. Am J Public Health. 2006;96(12):2186-93. 
13. Kimbro RT, Bzostek S, Goldman N, Rodriguez G. Race, Ethnicity, And The Education Gradient In Health. Health Aff (Millwood). 2008;27(2):361-72.

14. Sow M, Racape J, Schoenborn C, De Spiegelaere M. Is the socioeconomic status of immigrant mothers in Brussels relevant to predict their risk of adverse pregnancy outcomes? BMC Pregnancy Childbirth. 2018;18(1).

15. Defay F, Drouin C, Litvak É, Markon M-P, Springmann V, St-Arnaud-Trempe E, et al. État de situation sur la santé des Montréalais et ses déterminants. 2015. http://www.deslibris.ca/ID/245470

16. Sow M, Feyaerts G, De Spiegelaere M. Profil des nouveau-nés bruxellois et impact sur la santé périnatale. In: Pauvreté en Belgique: Annuaire 2017. Lahaye, Willy; Pannecoucke, Isabelle; Vranken, Jan; Van Rossem, R.; 2017. p. 147-67.

17. Noël A. The Politics of Minimum Income Protection in OECD Countries. J Soc Policy. 2019;48(2):227-47.

18. BCSS. Datawarehouse. Notion de revenu. https://www.kszbcss.fgov.be/fr/dwh/dwh_page/content/websites/datawarehouse/others/notion-derevenu.html

19. Statistics Canada. Dissemination area (DA). http://www12.statcan.gc.ca/censusrecensement/2011/ref/dict/geo021-eng.cfm

20. Denny K, Davidson M-J. Les indicateurs socioéconomiques régionaux: des outils de recherche, de politiques et de planification axés sur les disparités d'état sanitaire. Rev Can Santé Publique. 2012;103, supp 2:4-6.

21. Geronimus AT. Invited commentary: Using area-based socioeconomic measures--think conceptually, act cautiously. Am J Epidemiol. 2006;164(9):835-40; discussion 841-843.

22. Fréchet G, Hamzaoui M, Tran Q-V. La pauvreté, les inégalités et l'exclusion sociale au

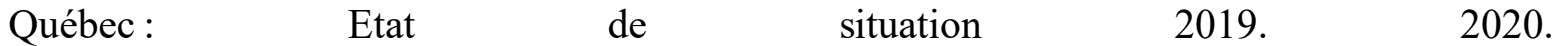
https://www.mtess.gouv.qc.ca/publications/pdf/CEPE_Etat-situation-2019.pdf

23. IWEPS. EU statistics on income and living conditions (calcul of IWEPS). 2020. https://www.iweps.be/

24. Institut de la statistique du Québec. Taux de faible revenu, selon le type de famille, par région administrative et ensemble du 2020. https://bdso.gouv.qc.ca/pls/ken/ken2123_navig_niv_3.page_niv3?p_iden_tran=REPEREYZ Z7935-1480806076576(Ab\&p_lang=1\&p_id_sectr=398

25. OECD. Poverty gap. OECD; 2020. https://www.oecd-ilibrary.org/social-issues-migrationhealth/poverty-gap/indicator/english_349eb41b-en 
26. OECD. Benefits in unemployment, share of previous income. OECD; 2020. https://www.oecd-ilibrary.org/employment/benefits-in-unemployment-share-of-previousincome/indicator/english_0cc0d0e5-en

27. OECD. Income inequality. OECD; 2020. https://www.oecd-ilibrary.org/social-issuesmigration-health/income-inequality/indicator/english_459aa7f1-en

28. Beltrán-Sánchez H, Palloni A, Riosmena F, Wong R. SES Gradients Among Mexicans in the United States and in Mexico: A New Twist to the Hispanic Paradox? Demography. 2016;53(5):1555-81.

29. Racape J, Schoenborn C, Sow M, Alexander S, De Spiegelaere M. Are all immigrant mothers really at risk of low birth weight and perinatal mortality? The crucial role of socio-economic status. BMC Pregnancy Childbirth. 2016;16:75.

30. Hultstrand JN, Tydén T, Målqvist M, Ragnar ME, Larsson M, Jonsson M. Foreign-born women's lifestyle and health before and during early pregnancy in Sweden. Eur J Contracept Reprod Health Care. 2020 Jan 2;25(1):20-7. https://www.tandfonline.com/doi/full/10.1080/13625187.2019.1706078

31. Melchior M, Chollet A, Glangeaud-Freudenthal N, Saurel-Cubizolles M-J, Dufourg M-N, van der Waerden J, et al. Tobacco and alcohol use in pregnancy in France: The role of migrant status. Addict Behav. 2015;51:65-71. https://linkinghub.elsevier.com/retrieve/pii/S0306460315002713 